\title{
Effect of solvent-vapour annealing on morphology, structure of copper(II) phthalocyanine thin films and device performance
}

\author{
JING XU ${ }^{1,2}$, XUEQIANG LIU ${ }^{3}$, WENLONG HOU ${ }^{1}$, HUIYUN GUO ${ }^{1}$, LAN YU ${ }^{1}$ \\ and HAIQUAN ZHANG ${ }^{1, *}$ \\ ${ }^{1}$ State Key Laboratory of Metastable Materials Science and Technology, Yanshan University, Qinhuangdao 066004, \\ People's Republic of China \\ ${ }^{2}$ Northeast Petroleum University, Qinhuangdao 066004, People's Republic of China \\ ${ }^{3}$ College of Information Science and Engineering, Yanshan University, Qinhuangdao 066004, People's Republic of China \\ *Author for correspondence (hqzhang@ysu.edu.cn)
}

MS received 2 August 2017; accepted 30 November 2017; published online 28 July 2018

\begin{abstract}
We investigate the molecular orientation transition and resulting morphology of copper phthalocyanine $(\mathrm{CuPc})$ thin films induced by solvent-vapour annealing (SVA) in detail. Seven solvents are utilized to tune the morphology of CuPc thin films. The morphology, crystalline structure and optical properties of the CuPc active layer were investigated through field emission scanning electron microscopy (FESEM), X-ray diffraction (XRD) and ultraviolet-visible (UV-Vis) absorption spectrum, respectively. The result demonstrates that morphology and structure are depended on the type of solvents. The high crystallinity of the CuPc films with a larger grain size and less grain boundaries can be observed. As a result, the resistance of the conducting channel is decreased, leading to an improved performance of the organic field-effect transistor (OFET).
\end{abstract}

Keywords. Copper phthalocyanine; morphology; structure; solvent-vapour annealing; organic field-effect transistor.

\section{Introduction}

Organic field-effect transistor (OFET) has attracted much attention for its promising application in organic electronics [1-10]. CuPc is used as active layer in OFET due to its low cost, high thermal and chemical stabilities and excellent field-effect characteristics [11-17]. The structure and morphology of $\mathrm{CuPc}$ thin films play an important role on the performance of OFET. It was shown that the high molecular orientation in thin films can increase the mobility of the devices and determine its intrinsic properties [11,18-25]. The low mobility and high threshold voltage have hindered their practical application in OFET $[15,26,27]$. In recent years, many researches focussed on changing the morphology of thin films and having the preferred orientation of thin films on the $\mathrm{SiO}_{2} / \mathrm{Si}$ substrate via various methods, such as substrate temperature [11,15,16], active layer material [28-30], active layer structure (amorphous or single crystal $[31,32]$ ), deposition rate [33], post-deposition annealing [34,35] and solvent-vapour annealing (SVA) [36-41]. The performance of OFET has a great improvement through these approaches and methodologies. Our study is to obtain high performance OFET by treating CuPc thin films with SVA.

In this study, bottom-gate and bottom-contact OFET are fabricated, $\mathrm{CuPc}$ is used as organic active layer material, the $p$-doped $\mathrm{Si}$ substrate as the gate electrode and copper $(\mathrm{Cu})$ metal as the source/drain electrodes. We have investigated the effect of SVA with seven different solvents on the morphology, crystalline structure and optical properties of $\mathrm{CuPc}$ thin films and electrical characteristics of OFET. The results suggest that the optimized $\mathrm{CuPc}$ thin films are obtained through petroleum ether vapour annealing and the performance of the corresponding OFET is improved greatly.

\section{Experimental}

The source CuPc powder (in $\beta$-form, purity $>99 \%$, obtained from J\&K chemical, China) taken in a quartz boat was heated in the high vacuum chamber. Petroleum ether (PE), benzene, acetone, tetrahydrofuran (THF), dichloromethane (DCM), $\mathrm{N}, \mathrm{N}$-dimethylformamide (DMF) and ethyl alcohol (EA) were analytical grades and used without further purification. Quartz glass/silicon wafers were cleaned in deionized water, acetone and isopropyl alcohol consecutively for $15 \mathrm{~min}$ by ultrasonic bath and dried with flowing nitrogen. Quartz glass/silicon wafers were boiled in concentrated sulphuric acid and hydrogen peroxide (ratio $7: 3$ ) for $20 \mathrm{~min}$ at $100^{\circ} \mathrm{C}$, and annealed with octadecyl trichlorosilane (OTS) in methylbenzene for $2 \mathrm{~h}$ at room temperature $\left(20^{\circ} \mathrm{C}\right)$. All $\mathrm{CuPc}$ thin films were deposited on Quartz glass/silicon wafers at a chamber pressure of $7 \times 10^{-4} \mathrm{~Pa}$. The rate of deposition and the thickness of the deposited $\mathrm{CuPc}$ thin films were maintained at $0.2 \AA \mathrm{s}^{-1}$ 
and $40 \mathrm{~nm}$, respectively. $\mathrm{CuPc}$ thin films were annealed for $1 \mathrm{~h}$ in different solvent-vapours (PE, benzene, acetone, THF, DCM, DMF, EA) at extremely dry and under ambient conditions. A $300 \mathrm{~nm}$ oxide layer used as gate dielectric has a capacitance of $8 \mathrm{nF} \mathrm{cm} \mathrm{cm}^{-2}$ (measured by an Agilent E4980A LCR meter) after OTS treating. A $80 \mathrm{~nm} \mathrm{Cu}$ film acting as source/drain electrode was deposited at a chamber pressure of $7 \times 10^{-4} \mathrm{~Pa}$ through a shadow mask, defining channel width (W) and length (L) of 1000 and $10 \mu \mathrm{m}$, respectively. The rate of deposition and the thickness of the deposited $\mathrm{Cu}$ film were maintained at $0.2 \AA^{-1}$ and $80 \mathrm{~nm}$. Based on CuPc as active layer, the molecular structure of $\mathrm{CuPc}$ and OFET configuration are shown in figure 1.

The CuPc thin films were characterized by FESEM, XRD, UV-Vis absorption spectrum. FESEM (model: Hitachi S4800II, Japan) was used to record the scanning electron micrographs (SEM) of the CuPc thin films. XRD of CuPc thin films were recorded at a scan rate of $2^{\circ} \mathrm{min}^{-1}$ by Seifert XRD 3000P Diffractrometer with $\mathrm{CuK} \alpha$ radiation $(0.15418 \mathrm{~nm})$. UV-Vis spectrophotometer (model: Lambda35, PE, USA) was used to record the absorption spectra of $\mathrm{CuPc}$ thin films at room temperature. The device performance was evaluated in air at room temperature by a Keithley 2400 Source Meter semiconductor analyzer.

\section{Results and discussion}

The morphology of $\mathrm{CuPc}$ thin films plays a critical role in determining their macroscopic semiconducting performance. FESEM images of $40 \mathrm{~nm}$ CuPc thin films annealed in different solvent-vapours for $1 \mathrm{~h}$ are shown in figure 2 . The image of CuPc thin films deposited on bare quartz is shown in figure $2 \mathrm{a}$, which shows that nanosized particles are uniformly distributed. The image of $\mathrm{CuPc}$ thin films annealed in $\mathrm{PE}$ vapour is shown in figure $2 \mathrm{~b}$, which shows some regular nanorods of nearly $50 \mathrm{~nm}$ width and length around from 400 to $700 \mathrm{~nm}$. The image of CuPc thin films annealed in benzene vapour is shown in figure $2 \mathrm{c}$, more dense packing of $\mathrm{CuPc}$ nanoribbons with different lengths ranging from 300 to $700 \mathrm{~nm}$ and width of nearly $80 \mathrm{~nm}$ was found to be deposited regularly. The image of $\mathrm{CuPc}$ thin films annealed in acetone vapour is shown in figure $2 \mathrm{~d}$, which shows clearly the sparse packing of nanosized nanobelt-like bamboo leaf with length of nearly $500 \mathrm{~nm}$ and different widths ranging from 50 to
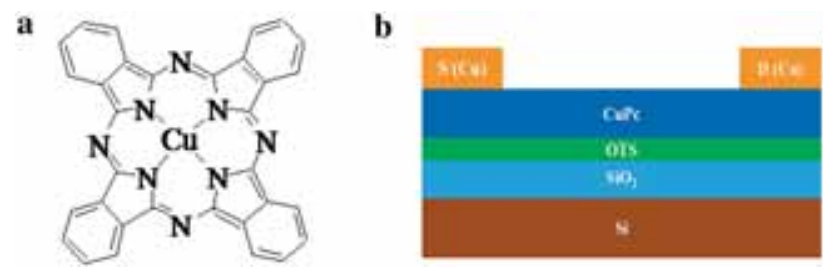

Figure 1. (a) Chemical structure of CuPc molecule and (b) the configuration of OFET.
$80 \mathrm{~nm}$. The image of CuPc thin films annealed in THF vapour is shown in figure $2 \mathrm{e}$, which shows clearly the dense and uniform packing of nanosized nanobelt-like bamboo leaf with length of nearly $400 \mathrm{~nm}$ and different widths ranging from 50 to $100 \mathrm{~nm}$. The image of CuPc thin films annealed in $\mathrm{DCM}$ vapour is shown in figure $2 \mathrm{f}$, which shows clearly the sparse and uniform packing of nanosized linear nanoribbons with length of nearly $600 \mathrm{~nm}$ and width of nearly $60 \mathrm{~nm}$. The image of $\mathrm{CuPc}$ thin films annealed in DMF vapour is shown in figure $2 \mathrm{~g}$, which shows clearly thick and nonuniform packing of rods with branches whose length is from 700 to $1.5 \mu \mathrm{m}$ and width is nearly from 100 to $120 \mathrm{~nm}$. The image of CuPc thin films annealed in EA vapour is shown in figure $2 \mathrm{~h}$, which shows a small number of nanorods in comparison with figure 2a. The morphology of CuPc thin films depends on solvent characteristics through the process of $\mathrm{CuPc}$ molecular rearrangement.

To elucidate the morphology transition process in detail, the FESEM images of $40 \mathrm{~nm} \mathrm{CuPc}$ thin films annealed in PE vapour for different immersion times are shown in figure 3. Figure 3a shows clearly almost uniform distribution of some small particles in nanoscale. Figure $3 \mathrm{~b}$ shows that the large-size nanorods are formed easily in PE vapour for only $10 \mathrm{~min}$. As the immersion time increased to $20 \mathrm{~min}$, the larger nanorods become visible in morphology with further immersion in figure $3 \mathrm{c}$. As the immersion time is increased to $60 \mathrm{~min}$, figure $3 \mathrm{~d}$ shows that there is little change in morphology compared to an immersion time of $20 \mathrm{~min}$. An immersion time of $20 \mathrm{~min}$ in PE vapour appears to be sufficiently long for a $40 \mathrm{~nm} \mathrm{CuPc}$ thin films to form the largest nanorods. Solvent molecules can penetrate into the CuPc thin films when the samples are immersed in PE vapour, the annealing process takes about $20 \mathrm{~min}$ and a equilibrium is achieved due to the poor solubility of CuPc in PE. The results in figure 3 also suggest that the formation of large-size nanorods and the morphology transition do not take place during immersion in PE, if not, the longer the immersion time, the greater the amount and size of the large-size nanorods. We can conclude that the formation of large-size nanorods takes place during solvent evaporation. Evaporation of the solvent molecules can induce rearrangement of the $\mathrm{CuPc}$ molecules in thin films. The more the amount of solvent in the films, the more the $\mathrm{CuPc}$ molecules will rearrange, resulting in an increased number of large-size nanorods (figure $3 b$ and $c$ ). The transition process should closely relate to solvent evaporation in the process of drying under ambient conditions. CuPc thin films with saturated solvent have almost the same evaporation time and show the similar morphology of CuPc thin films (figure $3 \mathrm{c}-\mathrm{d}$ ). These results suggest that the amount of absorbed solvent in the $\mathrm{CuPc}$ thin films and the evaporation rate of the solvent molecules are both important factors during the formation of large-size nanorods. This process is similar with copper hexadecafluorophthalocyanine $\left(\mathrm{F}_{16} \mathrm{CuPc}\right)$ thin films induced by solvent annealing [39]. The solvent properties, i.e., vapour pressure, evaporation rate and electronic interaction, play an important role in determining the film morphology. 


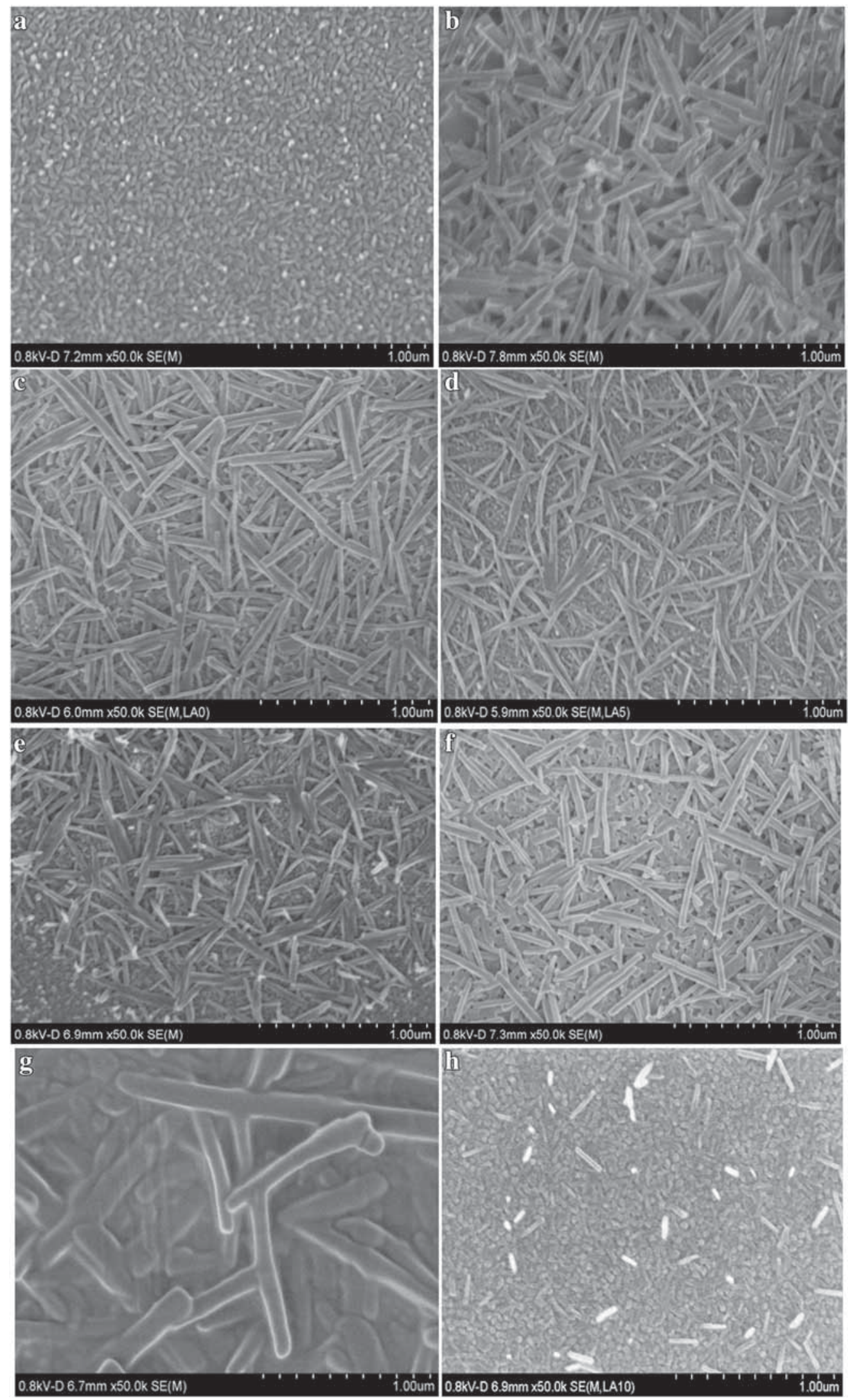

Figure 2. FESEM images of $40 \mathrm{~nm} \mathrm{CuPc}$ thin films annealed in (a) pristine; (b) PE; (c) benzene; (d) acetone; (e) THF; (f) DCM; (g) DMF and (h) EA vapour for $1 \mathrm{~h}$ and then dried under ambient conditions. 

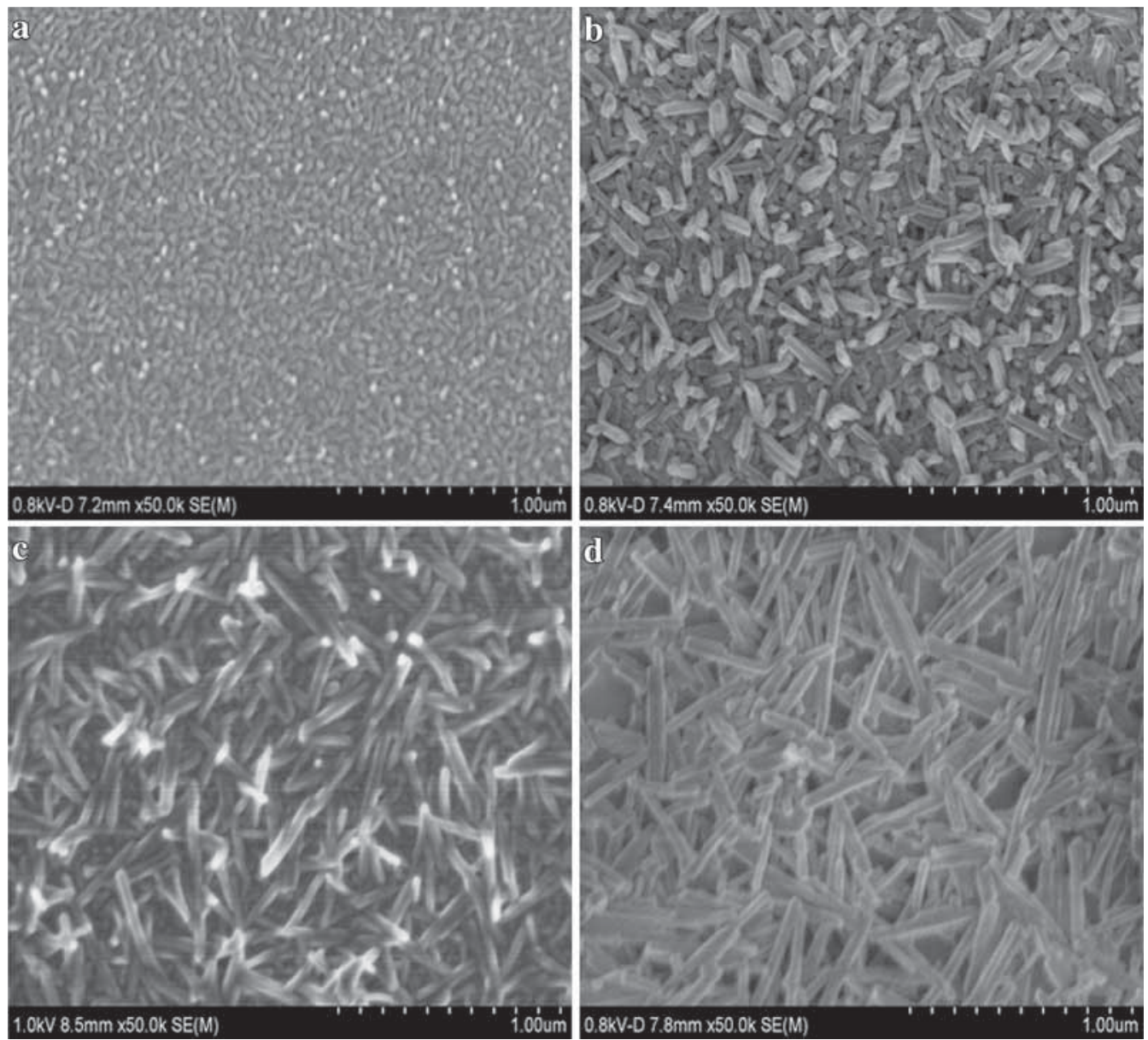

Figure 3. FESEM images of $40 \mathrm{~nm}$ CuPc thin films annealed in PE vapour for (a) 0, (b) 10, (c) 20 and (d) $60 \mathrm{~min}$.

The evaporation of solvent induces the $\mathrm{CuPc}$ molecules to move, leading to aggregation, nucleation and growth. The formation of large-size nanorods shows a close relationship with the amount of solvent absorbed in the films and the evaporation rate of the solvent. Slower evaporation rates and increased absorption by the solvent are both helpful in the formation of the larger nanorods. PE is a nonpolar solvent, the interaction between $\mathrm{PE}$ and $\mathrm{CuPc}$ is weak, hence, larger nanorods are formed. The interaction between EA explored most polar solvents and $\mathrm{CuPc}$ is strong, therefore, smaller nanorods are formed. The morphology of the CuPc thin films treated with other solvent vapour is between the two.

Figure 4 shows the XRD patterns for $40 \mathrm{~nm} \mathrm{CuPc}$ thin films deposited on bare quartz at room temperature $\left(20^{\circ} \mathrm{C}\right)$ with different SVAs for $1 \mathrm{~h}$ and then dried under ambient conditions. It can be seen from figure 4 that a single sharp reflection at $2 \theta$ of $6.9^{\circ}(d=12.8 \AA)$ corresponding to the (200) lattice plane of $\alpha$-phase of CuPc is observed $[15,28,42]$. Thus, solventvapour is different, since the position of the diffraction peak is not changed, which confirms that the $\mathrm{CuPc}$ thin films have the same polycrystalline structure. The reflection intensity at $6.9^{\circ}$ shows a corresponding increase and sharpening with different solvent-vapours, which indicates better ordering and enhanced crystallinity within CuPc thin films. The better $\mathrm{CuPc}$ thin films orientation, the stronger the diffraction peak intensity, the greater crystallinity, the resulting $\mathrm{CuPc}$ thin films look very promising for the fabrication of high-performance OFET. The diffraction peak of the annealed CuPc thin films in THF vapour has a small peak at a high diffraction angle. This suggests that the annealed films are in a transition process.

The crystalline size from XRD spectra $(D)$ was calculated using the Scherrer equation [33].

$$
D=\frac{k \lambda}{\beta \cos \theta},
$$

where $\beta$ is FWHM, $k$ the constant (with a value of 0.94 ), $\lambda$ the wavelength of the XRD and $\theta$ is the Bragg angle.

Figure 5 shows the relationship between the average crystalline size and the different SVAs for the $40 \mathrm{~nm} \mathrm{CuPc}$ thin films. The estimated average crystalline size changes from around $1.45 \mathrm{~nm}$ (Pristine) to $3.32 \mathrm{~nm}$ (PE) with different solvent-vapours. This indicates that the crystallinity of the 


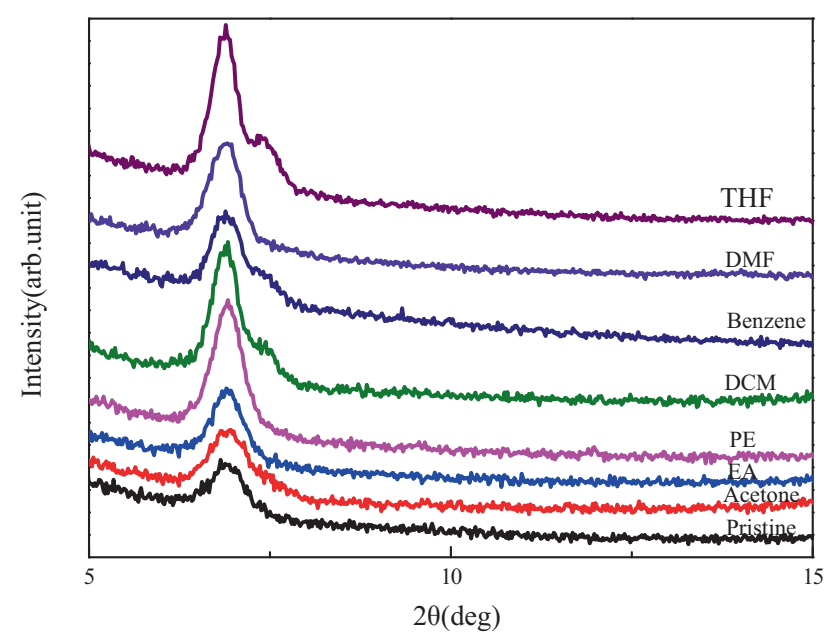

Figure 4. XRD patterns of $\mathrm{CuPc}$ thin films deposited on quartz, the representative curves in each figure give the pattern with different SVAs for $1 \mathrm{~h}$ and then dried under ambient conditions.

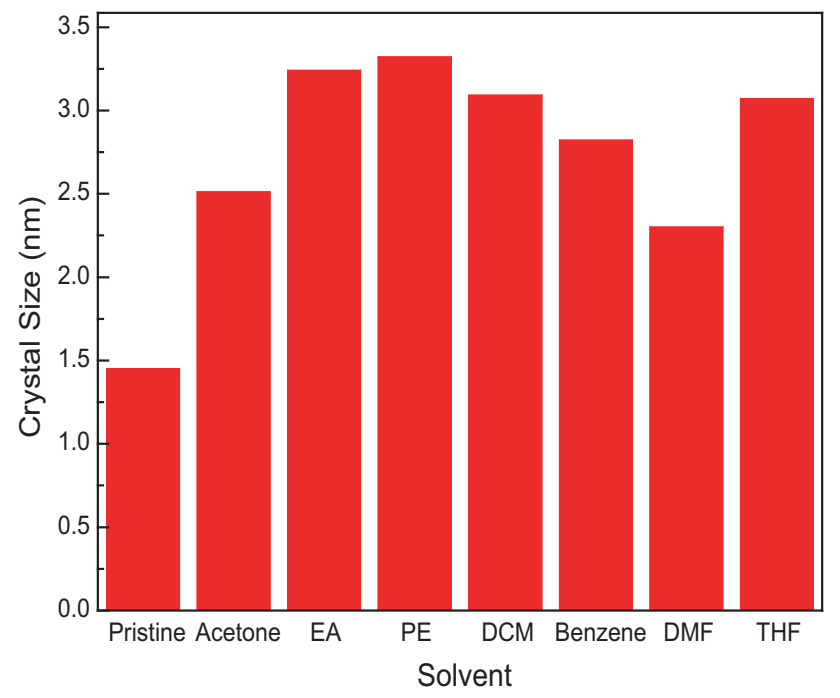

Figure 5. The average crystalline size calculated from the full width at half maximum (FWHM) of the XRD peak by using the Scherrer equation vs. $40 \mathrm{~nm} \mathrm{CuPc}$ thin films deposited on bare quartz at room temperature $\left(20^{\circ} \mathrm{C}\right)$ with different SVAs for $1 \mathrm{~h}$ and then dried under ambient conditions.

$\mathrm{CuPc}$ thin films is different with different solvents. The crystalline size of $\mathrm{CuPc}$ thin films annealed in PE vapour is the largest. Therefore, the corresponding OFET might show a better performance.

The optical absorption spectra of $40 \mathrm{~nm} \mathrm{CuPc}$ thin films deposited on bare quartz with different SVAs for $1 \mathrm{~h}$ and then dried under ambient conditions are recorded at room temperature $\left(20^{\circ} \mathrm{C}\right)$. The optical absorption spectra of $\mathrm{CuPc}$ thin films are shown in figure 6. Each curve represents the spectrum of $\mathrm{CuPc}$ thin films with a specific SVA. It is indicated that the UV-Vis spectrum of CuPc originates from the molecular orbitals within the aromatic $18-\pi$ electron system and from

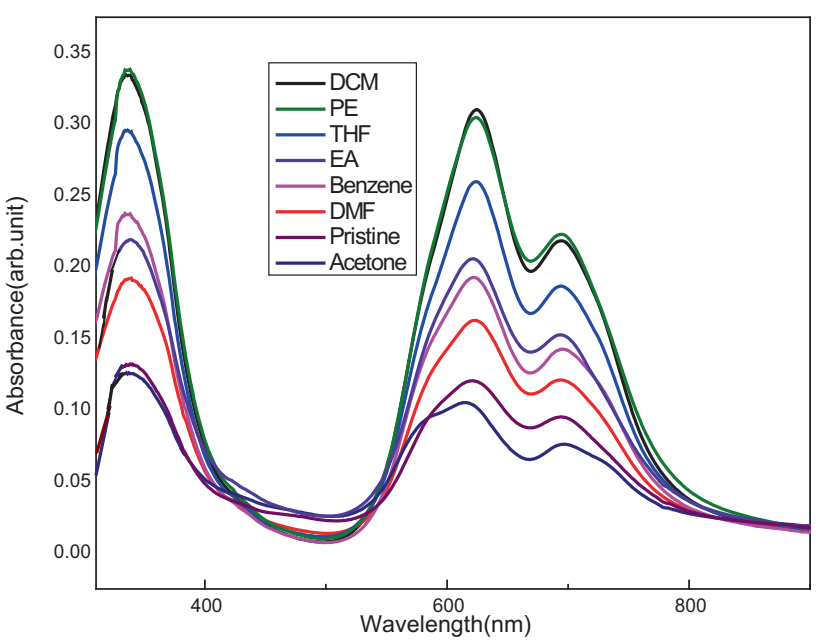

Figure 6. The optical absorption spectra and the representative curves in the figure give the pattern for different SVAs.

overlapping orbitals on the central metal [43]. In the near UV region, the B-band representing the $\pi \rightarrow \pi^{*}$ transition appears with peak position in the range about $329-349 \mathrm{~nm}$ depending on the nature of the substrate used [43,44]. The absorption band in the visible region for each sample film known as the Q-band representing the $\pi \rightarrow \pi^{*}$ transition [44] has a doublet due to Davydov splitting [45] with peak position in the range about $630-693 \mathrm{~nm}$ depending on the nature of substrate used. From figure 6, it is clear that the relative intensity of peaks annealed $\mathrm{CuPc}$ thin films depends on the specific solvent vapour, the relative intensity of peaks annealed $\mathrm{CuPc}$ thin films in PE vapour is the strongest and the relative intensity of peaks annealed $\mathrm{CuPc}$ thin films in acetone vapour is the weakest, the relative intensity of peaks of pristine CuPc thin films is weaker. The changes in the intensity of peaks annealed $\mathrm{CuPc}$ thin films in different solvent-vapours are attributed to the changes in the morphology and crystalline structure of $\mathrm{CuPc}$ thin films. In the Q-band, the intensity of higher energy peak is stronger than that of the lower energy peak, this behaviour represents the typical features of the $\alpha$-phase of $\mathrm{CuPc}$ [28], and the result is consistent with that of XRD.

To examine the relationship between physical properties of solvents for SVA and the OFET performances, we also inspect the effects of polarity of the solvents studied: EA (most polar solvent explored, solubility parameter $\delta=27.6 \mathrm{~J}^{1 / 2} \mathrm{~cm}^{-3 / 2}$ ), DMF, acetone, THF, DCM, benzene and PE (nonpolar, $\delta=$ $14.4-14.9 \mathrm{~J}^{1 / 2} \mathrm{~cm}^{-3 / 2}$ ) on structural rearrangement of $\mathrm{CuPc}$ and the OFET performance accordingly. Solvent physical properties and the OFET performance are listed in table 1. A summary of the OFET statistics for the saturation mobility $\left(\mu_{\mathrm{sat}}\right)$, the threshold voltage $\left(V_{\mathrm{T}}\right)$ and the on-off current ratio (on/off) after $1 \mathrm{~h}$ of SVA with each of the solvent is presented in table 1. The output characteristics of OFET with PE vapour annealing for $1 \mathrm{~h}$ is shown in figure 7 , which is the drainsource current $\left(I_{\mathrm{ds}}\right) v s$. the drain-source voltage $\left(V_{\mathrm{ds}}\right)$ for 
Table 1. Physical properties of solvents with SVA and the OFET performances.

\begin{tabular}{|c|c|c|c|c|c|c|}
\hline Solvent & Boiling point $\left({ }^{\circ} \mathrm{C}\right)$ & Vapour pressure $(\mathrm{kPa})$ & $\begin{array}{l}\text { Solubility parameter, } \\
\qquad \delta\left(\mathrm{J}^{1 / 2} \mathrm{~cm}^{-3 / 2}\right)\end{array}$ & $\mu_{\text {sat }}\left(\mathrm{cm}^{2} \mathrm{~V}^{-1} \mathrm{~s}^{-1}\right)$ & $V_{\mathrm{T}}(\mathrm{V})$ & On/off \\
\hline Pristine & & & & 0.00025 & 17 & $10^{2}$ \\
\hline EA & 78.32 & 5.333 at $19^{\circ} \mathrm{C}$ & 27.6 & - & - & - \\
\hline DMF & 153.0 & 0.5 at $25^{\circ} \mathrm{C}$ & 24.8 & - & - & - \\
\hline Acetone & 56.12 & 24.64 at $20^{\circ} \mathrm{C}$ & 20.5 & - & - & - \\
\hline $\mathrm{THF}$ & 66 & 23.46 at $25^{\circ} \mathrm{C}$ & 20.3 & - & - & - \\
\hline DCM & 39.75 & 46.5 at $20^{\circ} \mathrm{C}$ & 19.8 & 0.0033 & 11.5 & $10^{3}$ \\
\hline Benzene & 80.1 & 10.67 at $21.293^{\circ} \mathrm{C}$ & 18.7 & 0.0022 & 16 & $10^{3}$ \\
\hline $\mathrm{PE}$ & $40-80$ & 53.32 at $20^{\circ} \mathrm{C}$ & $14.4-14.9$ & 0.0038 & 12.3 & $10^{3}$ \\
\hline
\end{tabular}

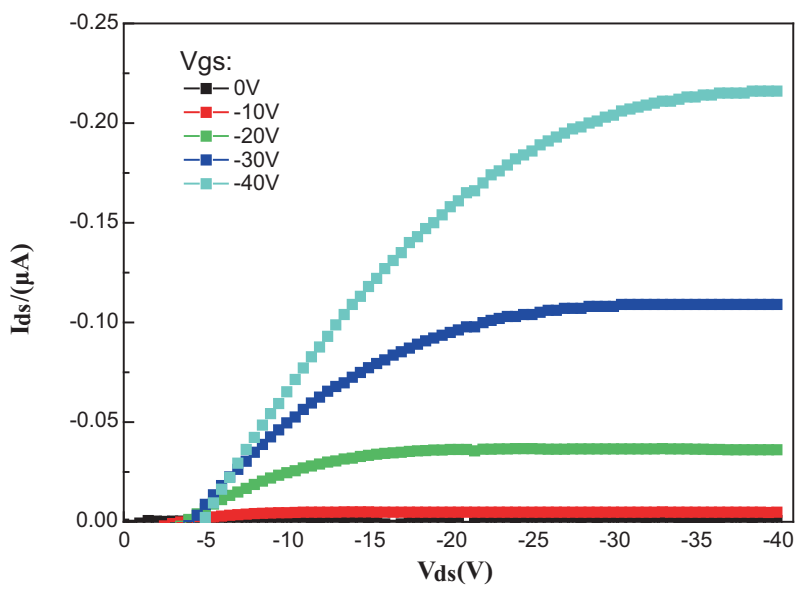

Figure 7. Output characteristics ( $I_{\mathrm{ds}} v s$. $V_{\mathrm{ds}}$, for different $V_{\mathrm{gs}}=0$, $10,20,30$ and $40 \mathrm{~V}$ ) of the OFET with PE vapour annealing for $1 \mathrm{~h}$.

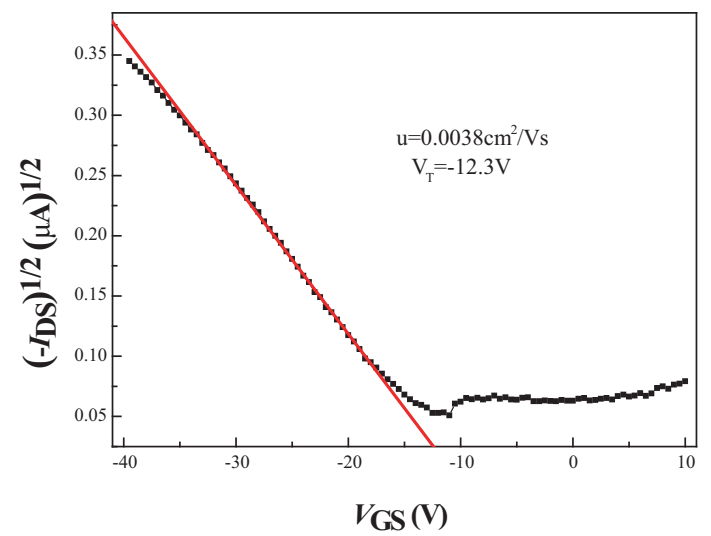

Figure 8. Transfer characteristics (the $\sqrt{/ I_{\mathrm{ds}} /}$ vs. $V_{\mathrm{gs}}$, for $V_{\mathrm{ds}}=20 \mathrm{~V}$ ) of the OFET with PE vapour annealing for $1 \mathrm{~h}$.

different gate-source voltages $\left(V_{\mathrm{gs}}=0,10,20,30\right.$ and $40 \mathrm{~V}$ ) of the OTFT, the transfer characteristics (the $\sqrt{/ I_{\mathrm{ds}} /} v s$. $V_{\mathrm{gs}}$, for $V_{\mathrm{ds}}=20 \mathrm{~V}$ ) of the OFET with PE vapour annealing for $1 \mathrm{~h}$ is shown in figure 8 . Table 1 shows the OFET characteristics with PE vapour annealing for $1 \mathrm{~h}$ are better than the OFET with benzene and DCM vapour annealing for $1 \mathrm{~h}$, the characteristics of OFET with THF, acetone, DMF and EA vapour annealing for $1 \mathrm{~h}$ and that of untreated OFET are very poor. We discern that the performance of OFET with PE vapour annealing $\left(\mu_{\mathrm{sat}}=0.0038 \mathrm{~cm}^{2} \mathrm{~V}^{-1} \mathrm{~s}^{-1}, V_{\mathrm{T}}=12.3 \mathrm{~V}\right.$, on/off $=10^{3}$ ) is much more effective than that of OFET with other SVAs. Most results are in accordance with the analytical results of SEM, XRD and UV.

\section{Conclusions}

In this study, the characteristic OFET based on $\mathrm{CuPc}$ were investigated. The morphology and molecular orientation of $\mathrm{CuPc}$ thin films are tuned using SVA. SVA leads to a rearrangement of $\mathrm{CuPc}$ molecules in thin films and results in large-size nanorods. The solubility parameter of solvent plays an important role in determining thin films morphology. We have analysed SEM, XRD, UV of CuPc thin films, output characteristics and transfer characteristics of the OFET. All results show the performance of OFET with PE vapour annealing for $1 \mathrm{~h}$ is the best. The resulting $\mathrm{CuPc}$ thin films tuned by SVA have a great prospect of application for the fabrication of high-performance organic electronic devices such as OFET.

\section{Acknowledgements}

This work was supported by the National Natural Science Foundation of China (NSFC) (Nos.: 51173155, 51472214) and the Natural Science Foundation of Hebei Province (No: E2017203247).

\section{References}

[1] Gundlach D J, Lin Y Y, Jackson T N, Nelson S F and Schlom D G 1997 IEEE Electr. Device L. 1887

[2] Dimitrakopoulos C D, Malenfant P R L and Mascaro D J 2001 IBM J. Res. Dev. 4511

[3] Forrest S R 2004 Nature 428911

[4] Veres J, Ogier S and Lloyd G 2004 Chem. Mater. 164543 
[5] Ruiz R, Choudhary D, Nicke B, Toccoli T, Chang K, Mayer A C et al 2004 Chem. Mater. 164497

[6] Park Y D, Lim J A, Lee H S and Cho K 2007 Mater. Today 10 46

[7] Bao Z N and Lockling J 2007 Organic field effect transistors (America: CRC Press, Taylor and Francis Group)

[8] Virkar A, Mannsfeld S, Oh J H, Toney M F, Tan Y H, Liu G Y et al 2009 Adv. Funct. Mater. 191962

[9] Chen X L, Lovinger A J, Bao Z N and Sapjeta 2001 J. Chem. Mater. 131341

[10] Swiggers M L, Xia G, Slinker J D, Gorodetersky A A, Malliaras G G, Headick R L et al 2001 Appl. Phys. Lett. 791300

[11] Bao Z N, Lovinger A J and Dodabalapur A 1996 Appl. Phys. Lett. 693066

[12] Bao Z N, Lovinger A J and Dodabalapur A 1997 Adv. Mater. 942

[13] Zhou X, Pfeiffer M, Blochwitz J, Werner A, Nollau A, Fritz T et al 2001 Appl. Phys. Lett. 78410

[14] Hoshino S, Kamata T and Yase K 2002 J. Appl. Phys. 926028

[15] Xiao K, Liu Y, Yu G and Zhu D B 2003 Appl. Phys. A 77 367

[16] Kumar P, Sharma A, Yadav S and Ghosh S 2013 Org. Electron. 141663

[17] Xiao K, Liu Y, Guo Y, Yu G, Wan L and Zhu D B 2005 Appl. Phys. A $\mathbf{8 0} 1541$

[18] Garnier F, Horowitz G, Fichou D and Yassar A 1996 Synth. Met. 81163

[19] Lin Y Y, Gundlach D J, Nelson S F and Jackson T N 1997 IEEE Electr. Device L. 18606

[20] Kline R J, McGehee M D, Kadnikova E N, Liu J and Fréchet J M 2003 J. Adv. Mater. 151519

[21] Liu S H, Wang W C M, Briseno A L, Mannsfeld S C B and Bao Z N 2010 Adv. Mater. 211217

[22] Yang J L and Yan D H 2009 Chem. Soc. Rev. 402634

[23] Singh T B and Sariciftci N S 2006 Annu. Rev. Mater. Res. 15094757199

[24] Wang H B, Zhu F, Yang J L, Geng Y H and Yan D H 2007 Adv. Mater. 192168
[25] Sullivan P, Jones T S, Ferguson A J and Heutz S 2007 Appl. Phys. Lett. 91 233114-1

[26] Tang Q X, Li H X, He M, Hu W P, Liu C M, Chen K Q et al 2010 Adv. Mater. 1865

[27] Schön J H, Berg S, Kloc C and Batlogg B 2000 Science 287 1022

[28] Karan S and Mallik B 2007 J. Phys. Chem. C 1117352

[29] Hong F, Guo X N, Zhang H, Wei B, Zhang J H and Wang J 2009 Org. Electron. 101097

[30] Sinha S, Wang C H, Mukherjee M and Yang Y W 2014 J. Phys. D: Appl. Phys. 471

[31] Xiao K, Li R J, Tao J, Payzant E A, Ivanov I N, Puretzky A A et al 2009 Adv. Funct. Mater. 193776

[32] Briseno A L, Aizenberg J, Han Y J, Penkala R A, Moon H, Lovinger A J et al 2005 J. Am. Chem. Soc. 12712164

[33] Onlaor K, Tunhoo B, Keeratithiwakorn P, Thiwawong T and Nukeaw J 2012 Solid State Electron 7260

[34] Parhi A P and Iyer S K 2013 J. Cryst. Growth 380123

[35] Wang C Y, Cho C P and Perng T P 2010 Thin Solid Films 518 6720

[36] Dickey K C, Anthony J E and Loo Y L 2006 Adv. Mater. 18 1721

[37] Di C A, Lu K, Zhang L, Liu Y Q, Guo Y L, Sun X N et al 2010 Adv. Mater. 221273

[38] Liu C, Minari T, Lu X B, Kumatani A, Takimiya K and Tsukagoshi K 2011 Adv. Mater. 23523

[39] Yang J L, Schumann S and Jones T S 2011 Thin Solid Films 5193709

[40] Miller S, Fanchini G, Lin Y Y, Li C, Chen C W, Su W F et al 2008 J. Mater. Chem. 18306

[41] Savage R C, Orgiu E, Mativetsky J M, Pisula W, Schnitzler T, Eversloh C L et al 2012 Nanoscale 42387

[42] Jungyoon E, Kim S, Lim E, Lee K, Cha D and Friedman B 2003 Appl. Surf. Sci. 205274

[43] Ough E A, Stillman M J and Creber K A M 1993 Can. J. Chem. 711898

[44] Mack J and Stillman M J 2001 Inorg. Chem. 40812

[45] Misra T N 1965 Rev. Pure Appl. Chem. 1539 